\title{
Editorial
}

\section{Joachim Szodruch}

Published online: 16 August 2011

(c) Deutsches Zentrum für Luft- und Raumfahrt e.V. 2011

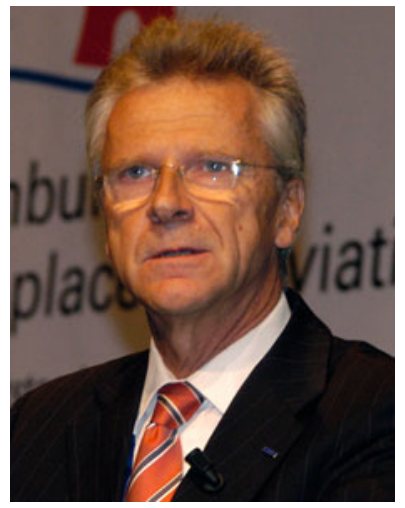

With this first issue of the all-new CEAS Aeronautical Journal the Council of European Aerospace Societies (CEAS) is proud to offer scientists and engineers in Europe and around the world a first-class journal for the publication of their high-quality research, technological and developmental results. The CEAS would like to thank the German Aerospace Center (DLR) for creating this journal, thus realising a new milestone in European scientific publications.

In the past decades Europe has produced a number of various journals offered in different nations and organisations. However the increasing cooperation within the European scientific environment and the merging of various organisations, specifically also in the industry, have stimulated the need to reduce fragmentation and to create a powerful European scientific journal. The CEAS member societies started to push for a new common approach some

J. Szodruch $(\bowtie)$

Thelsys GmbH Blohmstrasse 12, 21079 Hamburg, Germany

e-mail: Joachim.Szodruch@thelsys.de

years ago. As a matter of fact it was an early decision to cover the entire field of aerospace and therefore under the leadership of the DLR and ESA (European Space Agency), two new journals were launched with Springer, the present aeronautical one and in parallel the "CEAS Space Journal".

Over the past two or three decades the European research and technology base has not only moved closer together but developed into a worldwide top-class scientific community in terms of its quality and quantity. In order to secure and further develop these achievements an independent approach to scientific publications is required. Conserving know-how, generating synergy effects, promoting scientific communication, and stimulating a broader understanding of scientific and engineering work were some of the main reasons for creating this journal. With the intention of providing broad and interdisciplinary coverage of aeronautical topics, the journal is a mandatory contribution to Europe's high-quality aeronautical research, technological and developmental environment. As an example this first issue predominantly focuses on helicopter topics, a highly successful and competitive research, engineering and industrial sector in Europe.

All who contributed and were engaged in realising this first issue can be proud of the results. I would like to thank everyone involved but can only mention a few here: first Mrs. Silvia Schilgerius from Springer for her positive attitude and our many fruitful discussions, secondly the commitment of the initial Editor-in-Chief Prof. Andreas Dillmann from the DLR as well as the Managing Editor Dr. Hans-Peter Kreplin, the entire Editorial Board and the many Field Editors, all of whom accepted the task without hesitation. The support of all the members of the Board of the CEAS was essential and is highly appreciated. 
As the largest European aerospace research establishment, the German Aerospace Center was essential, and without the contribution of the DLR this journal would not have been possible. I am also very grateful to Prof. Rolf Henke, Member of the Executive Board of the DLR, who supported the journal in its final stages and furthermore agreed to assume the role as present Editor-in-Chief. Prof.Henke's dedication and future support are greatly appreciated.
I am sure this CEAS Aeronautical Journal will play an important role in Europe and around the globe, and with your support and contribution it will advance high-level aeronautical scientific and engineering work for the benefit of our mobile society.

Joachim Szodruch

CEAS President 2009 and 2010 